\title{
Zonal Operations: a method to rationalise operations
}

\author{
W. M. Guzman, K. J. Peszynski \& L. W. Young \\ School of Business Information Technology and Logistics, \\ College of Business, RMIT University, Australia
}

\begin{abstract}
In August 2013 and for the third consecutive year, Melbourne has been accredited as the most liveable city in the world. However, the city is also known and credited for a less attractive reason as "The City of Level Crossings"; the city's metropolitan area is home to 170 railroad level crossings (RLX).

Since 2006, Melbourne has experienced unprecedented train patronage demand. Victorian transport authorities, facing capacity, demand and overcrowding problems, have acquired new train sets, established new timetables that introduced additional urban train services, and prepared long term plans to address the issue. However, the additional train services result in a 'catch 22' situation. The additional train traffic causes extra boom gate activity at railroad level crossings, which in turns leads to additional vehicles congestion on Melbourne's roads.

This research investigates and proposes the introduction of Zonal Operations (ZO) in the Caulfield Group corridor that includes some of Melbourne's longest and busiest lines within the rail network. The research discusses the concept of $\mathrm{ZO}$, analyses the claim that $\mathrm{ZO}$ resolves capacity and overcrowding problems, a claim proposed in research literature. In addition, this research confirms that $\mathrm{ZO}$ has the potential to reduce the number of times boom gates are lowered at RLXs, and to mitigate road traffic congestion at RLXs. By doing this, a better understanding is gained in how $\mathrm{ZO}$ in railways can be used to mitigate road traffic congestion issues at RLX locations.
\end{abstract}

Keywords: railroad level crossings, Zonal Operations, time tables. 


\section{Introduction}

The Melbourne rail network faces demand, capacity and overcrowding problems caused by large increases in patronage $[1,2]$. Areas of the network have been considered to be unable to adequately handle the current patronage demand, let alone any growth due to population increases [3].

During the last decade, Melbourne experienced unprecedented train patronage demand increases, from 118.0 million to 225.0 million passengers per year. The large growth in patronage stretched the capacity of the rail network; it is estimated patronage demand will continue to grow, albeit not at the same rate of $10 \%$ per year or more patronage demand experienced in the past [3]. Public Transport Victoria (PTV), the authority responsible for coordinating public transport in the State of Victoria, Australia and network operators are struggling to cope with patronage demand increases and the resulting passenger overcrowding. Some lines in the Melbourne network experience between 45,000 and 75,000 passengers boarding, in both directions, per day.

Melbourne travel demand information from the East West Needs Assessment (EWLNA) indicates that " a two-track passenger railway can carry up to 25,000 passengers an hour in each direction" [1]. International standards indicate that the number of passengers in a single direction deemed appropriate for an urban rail line, is around 60,000 passengers per hour [4, 5]. By these standards, Melbourne's volume of patronage makes the network lines "lightly-loaded urban rail corridor [s]" $[5,6]$ in comparison to similar lines overseas. This suggests that the Melbourne network does not have capacity problems and should not be experiencing overcrowding. Research further indicates that the real problem is related to the inefficient operations of the rail network, which is affecting line capacity and causing overcrowding [5-8].

This research proposes that implementing Zonal Operations (ZO) in some lines can help resolve the lines capacity and overcrowding problems, as well as improving the efficiency of the rail networks operations [5, 9-11]. Thus, this research proposes the introduction of $\mathrm{ZO}$, incorporating new servicing patterns with scheduling and timetables that introduce best practice into the operation of some lines of the network. Best practices are derivative from an international operation modal established in Europe and already in use in Australia, in lines such as Perth's Northern Suburbs [5].

Therefore, this paper proceeds with a literature review of the Melbourne train network and its patronage; it analyses current train timetables and the operational modal of specific Melbourne rail corridors. This is followed by a review of the current approach to resolve capacity and overcrowding problems. Finally, a review of the concept of $\mathrm{ZO}$ as an alternative solution to the rail lines problems, specifying how this approach could be implemented and the benefits that could be derived from such implementation. 


\section{The Melbourne rail network}

The first railway line in Australia opened in Melbourne on 12 September 1854. Today, the network consists of 16 radial lines divided into five separate groups currently servicing more than 210 stations [12]. Figure 1 provides a view of the entire urban rail network.

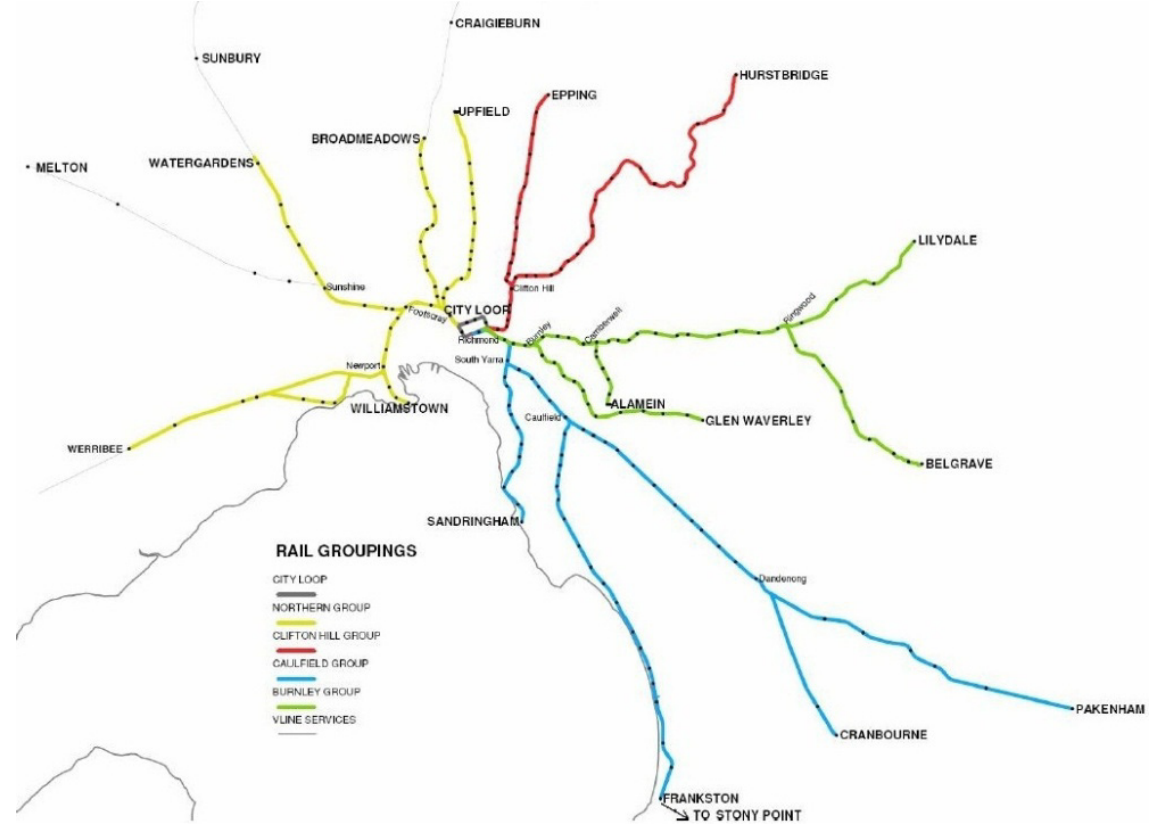

Figure 1: Melbourne rail network groups (source: EWLNA [1]).

The Melbourne rail network is used by a number of operators. The urban network is operated by Metro Trains. V/Line also operates rural and regional services and shares some tracks with the urban network; freight operators have limited use of some lines. By world standards, Melbourne's urban rail network is extensive; it is similar in size to the London Underground and larger than the Paris Metro [11]. However, that is where the similarities end, as the Melbourne network patronage of 222 million passengers per year in 2011-12 [13] is small in comparison to other countries. For instance, during the same period, Tokyo Metro patronage was 3,102 million passengers or 14 times larger than that of Melbourne.

The Department of Transport (DoT) and network operators were unprepared to deal with the large surge in patronage of the last decade and argued that there is little or no capacity left on many of the network rail corridors, including the City Loop, to accommodate such large patronage demand surges $[6,11,14]$.

The growing patronage demand resulted in an increase in overcrowding on many of the rail lines services [15]. Melbourne's urban trains regularly carry 
1,100 passengers or more, with one in six of the city's suburban trains overcrowded (a six-carriage train is considered overcrowded when it carries more than 798 passengers, or 133 passengers per carriage) [16]. The public is suffering the consequences of the problems of overcrowding, late running and cancellations of services. These are all said to be the result of poor planning and management by the rail operator and the DoT; the timetables service patterns used, the late running of services, as well as regular cancelation of services, contributes to overcrowding and inefficient service delivery $[5,6]$.

Towards the end of 2009, the contract to run the Melbourne train network was awarded to Metro Trains Melbourne; Metro inherited the capacity, constraints, patronage, and overcrowding problems of the network. In May 2011, Metro introduced new timetables throughout the network that provided 635 new weekly services [17]; this was based on the assumption that more capacity could be achieved by scheduling more trains. However, in order to introduce the additional services to operate on a said "at capacity" network, operational changes had to be made.

The additional services have been a welcome relief to train commuters, but have created a 'catch 22' situation at the 170 railway RLXs that gives Melbourne the not so distinguished title of "The City of Level Crossings" [18]; the extra services has caused additional activity at all RLXs, which in turns leads to further vehicles congestion on Melbourne's roads [19].

During 2010, the Department of Transport was overhauled, renamed and rebranded as Public Transport Victoria (PTV). In 2012, PTV developed a new transport plan, Plan Melbourne, Metropolitan Planning Strategy [20]. Plan Melbourne contains transport projects that would transform the efficiency and capacity of Melbourne's transport network for years to come [20, 21]. These significant projects, each costing taxpayers AUD\$10 billion dollars or more, would be completed over 20 years or longer.

However, the delayed implementation of these proposed solutions of building multibillion dollar projects, are the reasons why the Caulfield Group has been chosen as a case for the implementation of the concept of zonal operations. It is expected ZO will alleviate capacity and overcrowding problems faced by the Caulfield Group as soon as implemented. In the process, it is also anticipated that the implementation of $\mathrm{ZO}$ would mitigate road traffic congestion at all RLXs along the railway lines of the Caulfield Group.

\section{The Caulfield Group of lines}

Two of the busiest lines in the network services the south-eastern part of the metropolitan area and belong to the Caulfield Group of lines. The group consists of four corridors: Sandringham, Frankston, Pakenham and Cranbourne lines (the Dandenong line is serviced by both the Pakenham and Cranbourne lines); the group lines are presented in Figure 1 in blue colour. The lines share six tracks from the City to South Yarra where the Sandringham line separates, taking two tracks. At Caulfield, the remaining lines separate, with the Frankston line taking two tracks and the Dandenong lines (the Pakenham and Cranbourne lines) taking 
the remaining two tracks. The group of lines is also home to a total of 68 RLXs. Of these, 36 are RLXs located away from railway stations; 32 are RLXs located at, or in the vicinity of, railway stations. Figure 2 is indicative of the Dandenong and Frankston rail corridors and also displays the inexact locations and type of RLXs on these corridors.

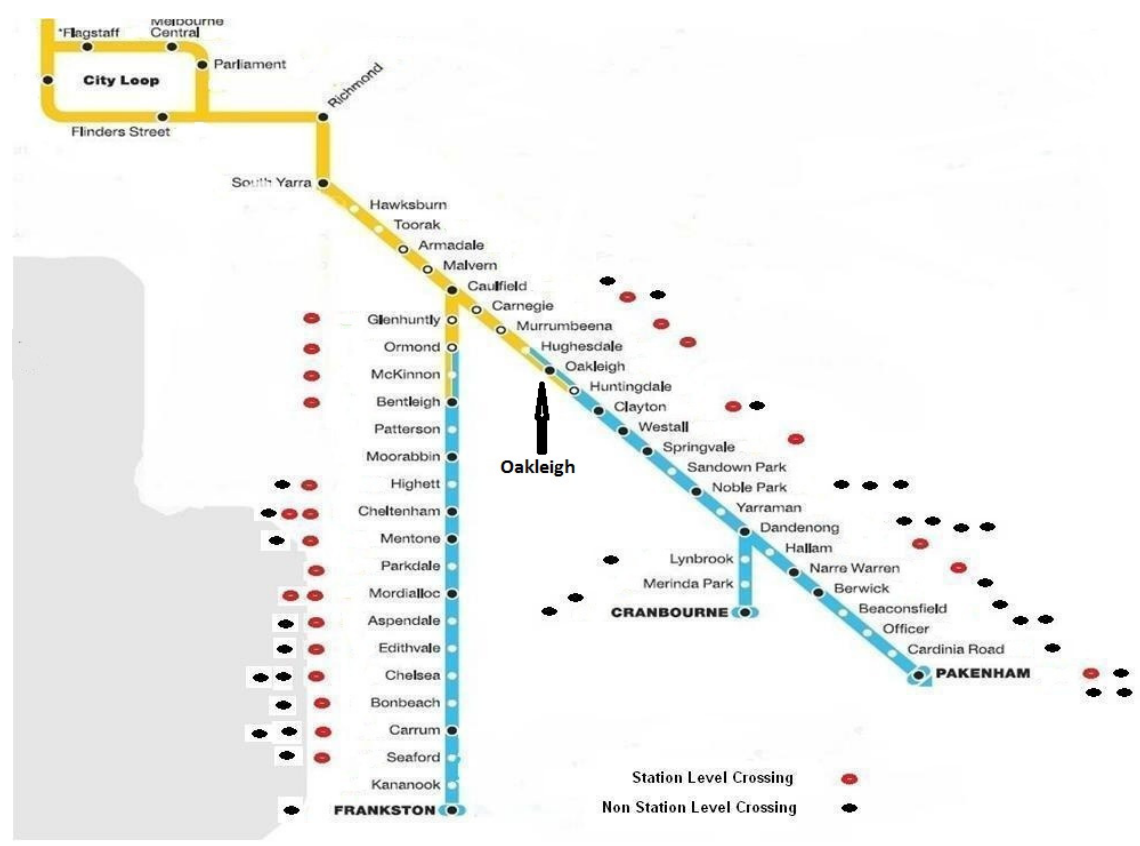

Figure 2: Dandenong and Frankston lines and RLXs locations.

\subsection{Caulfield Group services and patronage}

A review of the 2013 timetables for Metro and V/Line services along the corridors indicate that the total daily traffic at Caulfield Station is 504 train services per day [22-24]. Metro schedules 434 services per day and also runs 27 unscheduled out of service movements every day, giving Metro a total 461 movements per day. V/Line provides 43 services per day [22-24].

Published estimates indicate the Frankston line patronage at around 45,000 boarding's per day [5]. Published estimates indicate the Dandenong lines patronage at around 60,000 boarding's per day [5]. During 2013 and for the first time, PTV published figures from a train stations patronage Origin and Destination Survey (OD) [25]. The estimates are indicative of entries into stations and are said to be the best estimates currently available. The counts are based on entries to each station and are not a precise estimate of entries, growth of patronage or indicative of the intended direction of travel; a person entering a station precinct is recorded, but not the destination of the journey [25]. 
Reviewing the timetables of the lines services with patronage figures from the OD survey revealed some concerns. Of note, the Cranbourne line's current services seem out of proportion in relation to patronage. The total daily patronage entries into the three Cranbourne line stations, assuming all the patronage is in one direction towards Dandenong, is indicated as 4,528; yet, 54 train services originate from Cranbourne to the City during the day [22]; these services are sufficient to accommodate ten times that demand, suggesting the Cranbourne line is over-serviced.

Melbourne timetables are aligned towards the CBD with Melbourne's Flinders Street and Southern Cross as central stations, where most, if not all, services terminates [26]. With these patterns, all services cover most if not all stations along the lines; some services stopping at all stations and some services running several different express patterns [27].

The East-West Link Needs Assessment (EWLNA) review identified six or seven different train stoping patterns in some lines; these patterns are confusing for commuters and have the negative effect of reducing line capacity [1]. These types of arrangements are the result of poor scheduling and causing uneven services, with non-regular intervals to be followed (by commuters) [6]. Justification for these uneven patterns of services is said to be needed to accommodate V/Line's express rural services along the Pakenham corridor [5]. In addition, these service patterns do not correspond to patterns identified by Vuchic [4], patterns described under the Zonal Operations discussion.

For example, morning peak timetables for Dandenong lines-City bound commuters from Carnegie, indicate the following 16 Metro services [22]:

- a train at 7:06 am, preceded by an eleven-minute gap from the previous service, followed by seven services to $7: 59$ am with intervals of $3,6,10$, 10, 8, 7 and 9 minutes (7:09, 7:15, 7:25, 7:35, 7:43, 7:50 and 7:59);

- then a six-minutes gap for the 8:05 am service, followed by seven services to $8: 58$ am with intervals of $6,7,11,3,11,7$ and 9 minutes $(8: 11,8: 18,8: 29,8: 32,8: 43,8: 49$ and 8:58).

The Frankston line timetables have similar uneven services, but with the difference that the line does not need to accommodate $\mathrm{V} /$ Line express rural services.

\subsection{The Frankston and Dandenong lines corridors}

Metro uses the Frankston line to service suburban stations. Several operators use the Dandenong lines corridor; Metro uses the lines to service the suburban stations with services to Dandenong, Pakenham and Cranbourne; V/Line uses the lines for regional services to Bairnsdale and Traralgon; freight operators use the lines as well.

The Frankston line is 43.9 kilometres in length, services 26 stations and shares servicing of seven stations with the three Dandenong lines and two stations with the Sandringham line. The Pakenham line is 58.2 kilometres in length from the CBD; the Cranbourne line is 45.1 kilometres in length from the CBD; the Dandenong line is 31.2 kilometres in length from the CBD. In all, 
the lines services 29 stations: combined, they service 19 stations to Dandenong; the Pakenham line services an additional seven stations from Dandenong; the Cranbourne line services an additional three stations from Dandenong. The lines share the servicing of seven stations with the Frankston line and two stations with the Sandringham line.

\section{Current operations}

The timetables in operation since May 2011, provided limited short-term relief for rail commuters, but at the same time have created much bigger problems. For instance, the Frankston line now services mid-stations, stations bypassed under old timetables; most services are direct to Flinders St and not via the City Loop as previously, except for a small number of services during peak periods; these changes affect many, if not most, of the lines 45,000 commuters. Further, these changes force the line's commuters to change services at Caulfield, South Yarra or Richmond stations (refer to Figure 2 for details and stations location).

The current operations of the Dandenong lines are via the City Loop, bypassing most mid-stations between Caulfield and South Yarra, except during morning off-peak, when some of the services do stop at the mid-stations. The current operation of the Frankston line is $90 \%$ of traffic direct to Flinders St, stopping at all mid-stations between Caulfield and South Yarra; the remaining $10 \%$ of traffic are via the City Loop, bypassing all mid-stations between Caulfield and South Yarra, which are then serviced by the Dandenong lines services.

The introduction of new timetables and additional services provided some relief to rail commuters, but have had negative ramifications to road users; the added train traffic generates additional activity at RLXs, activity that aggravates road traffic congestion at all RLXs locations. The operation of the lines is presented in Figure 3. The diagram is indicative of the current operation of the Dandenong and Frankston lines services to the city.

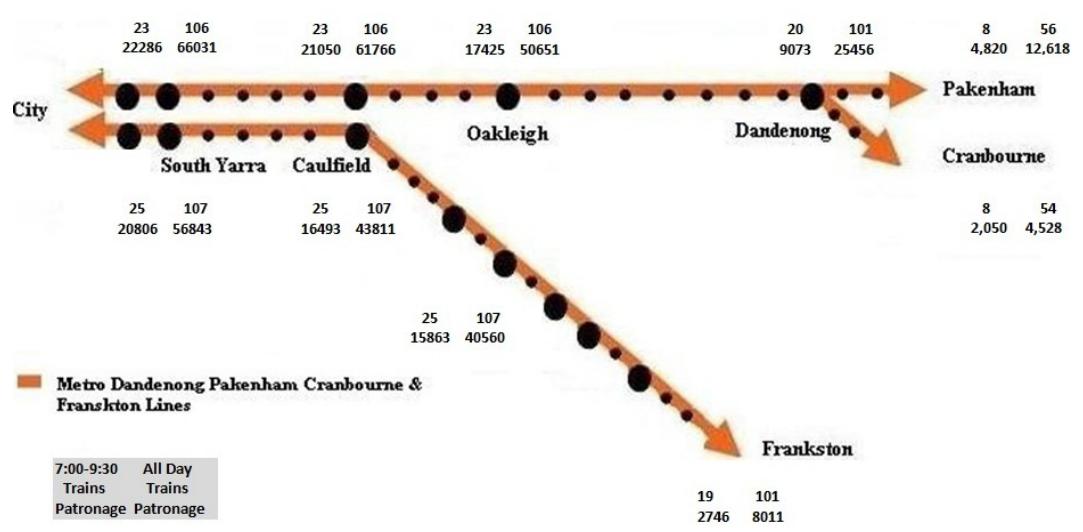

Figure 3: Current operations - Dandenong and Frankston lines. 
Train services and patronage figures per line sections are provided in groups of four. The upper figures indicate the number of the lines services for the 7:00-9:30 morning, and the All Day (18 hrs.) periods; the lower figures indicate the (weighted) patronage for the section during the corresponding periods.

\section{The Zonal Operation (ZO) concept}

Rail Zonal Operations are used in many places around the world [4, 5, 28]. ZO makes use of available infrastructure to better manage the available resources (rolling stocks, station platforms, turnbacks, etc.). In ZO, a rail line service is divided into two or more sectors called zones, and each zone is serviced by its own set of trains [4].

There are three types of transport operational modals identified by Vuchic (2005); these are: (a) Skip-Stop Operations, which refers to the only method that increases speed of traffic in a two-track rail network while maintaining high frequency and high line capacity; (b) Zonal Operations, which refers to when a line is divided in two or more sections, referred to as zones, where each zone is serviced by different sets of trains; and (c) Express/Local Operations, which refers to the only way to provide a combination of regular services among all stations as well as higher-speed services stopping only at major stations [4]. None of these services are in used in the Melbourne's network operations $[5,6]$.

\subsection{The proposed approach}

Introducing $\mathrm{ZO}$ operations to the Caulfield Group of lines can be accomplished by the creation of a new service, the Oakleigh-City-Oakleigh service, using currently under-utilised infrastructure at Oakleigh. Oakleigh Station infrastructure consists of three tracks and three platforms, allowing for services to originate or terminate from it.

This Oakleigh-City-Oakleigh service would operate directly to Flinders St. The services will be standard services stopping at all stations to the city, servicing the ten stations to Flinders St. Commuters requiring access to the City Loop and the CBD area will be required to change services at either at Caulfield, South Yarra or Richmond stations.

Frankston line services would service all stations to Caulfield, continuing the journey as an Express Service from Caulfield, stopping only at nominated stations. In addition, all Frankston line services would operate via the City Loop at all times, bypassing four mid-stations serviced by the Oakleigh-City-Oakleigh service.

Pakenham and Dandenong services would service all station stops to Oakleigh, continuing the journey as express services from Oakleigh, stopping only at nominated stations. All Dandenong lines services would operate via the City Loop at all times, bypassing the seven mid-stations serviced by the Oakleigh-City-Oakleigh services.

The Cranbourne line would continue to be serviced by shuttle services, as currently done during early morning and late evening, but the new service would 
expand the shuttle services to all times. All Cranbourne line commuters would change to connecting services at Dandenong to Pakenham or Dandenong services. In addition, it is proposed that previous traffic originating from Cranbourne to originate from Dandenong.

Both the Dandenong lines and Frankston line services would operate as express services; the proposed operational modal of the services would be $7 / 20 / 30$ minute patterns of services. This means that peak period services are every seven minutes or nine services per hour; interpeak services are every 20 minutes or three services per hour; and early morning and late evening services are every 30 minutes or two services per hour.

The Oakleigh-City-Oakleigh service would be 10/20/30 minute patterns of services. This means that peak period services are every ten minutes or six services per hour; interpeak services are every 20 minutes or three services per hour; and early morning and late evening services are every 30 minutes or two services per hour.

The introduction of $\mathrm{ZO}$ on the Dandenong and Frankston lines corridors would permit immediate downward rescheduling of services on these lines and the introduction of the brand new Oakleigh-City-Oakleigh services. As previously indicated, Metro's combined level of services at the lines at a common point at Caulfield, is 461 service movements per day. Instead, the introduction of ZO will provide 390 services per day across all of these lines. A summary of these figures is presented in Table 1.

Table 1: $\quad$ Proposed ZO services and patronage Oakleigh, Dandenong and Frankston lines.

\begin{tabular}{|c|c|c|c|c|c|c|c|c|c|}
\hline & $\begin{array}{c}\text { Current } \\
\text { Trains } \\
\text { Services } \\
\text { 7:00-9-29 } \\
\end{array}$ & $\begin{array}{l}\text { Current } \\
\text { Trains } \\
\text { Sevices } \\
\text { AM } \\
\end{array}$ & $\begin{array}{c}\text { Current } \\
\text { Trains } \\
\text { Sevices } \\
\text { PM } \\
\end{array}$ & $\begin{array}{l}\text { Current } \\
\text { Trains } \\
\text { Services } \\
\text { All Day } \\
\end{array}$ & $\begin{array}{l}\text { Proposed } \\
\text { Trains } \\
\text { Services } \\
7: 00-9 \cdot 29 \\
\end{array}$ & $\begin{array}{l}\text { Proposed } \\
\text { Trains } \\
\text { Services } \\
\text { AM } \\
\end{array}$ & $\begin{array}{c}\text { Proposed } \\
\text { Trains } \\
\text { Sevices } \\
\text { PM } \\
\end{array}$ & $\begin{array}{l}\text { Proposed } \\
\text { Trains } \\
\text { Services } \\
\text { All Day } \\
\end{array}$ & $\begin{array}{l}\text { dProposed } \\
\text { Difference } \\
\text { s }\end{array}$ \\
\hline Pakenham-Cranbourne to City - via City Loop & 23 & 50 & 55 & 106 & 17 & 30 & 38 & 68 & -38 \\
\hline Frankston to City - New via City Loop & 25 & 50 & 57 & 107 & 17 & 30 & 38 & 68 & -39 \\
\hline New Oakleigh ZO to City & & & & & 12 & 25 & 34 & 59 & 59 \\
\hline Total Services to City & 48 & 100 & 112 & 213 & 46 & 85 & 110 & 195 & -18 \\
\hline City to Pakenham-Cranbourne - Via City Loop & 20 & 36 & 73 & 109 & 17 & 30 & 30 & 68 & -41 \\
\hline Frankston to City - New via City Loop & 27 & 47 & 70 & 117 & 17 & 30 & 30 & 68 & -49 \\
\hline New City ZO to Oakleigh & & & & & 12 & 25 & 34 & 59 & 59 \\
\hline Total Services from City & 47 & 83 & 143 & 226 & 46 & 85 & 94 & 195 & -31 \\
\hline Total Services & 95 & 183 & 255 & 439 & 92 & 170 & 204 & 390 & -49 \\
\hline
\end{tabular}

The proposed ZO concept, the operation of the Dandenong and Frankston lines, including the new Oakleigh services to the city, are prescribed in Figure 4. Train services and patronage figures per line sections are provided in groups of four. The upper figures indicate the number of the lines services for the 7:00-9:30 morning, and the All Day (18 hrs.) periods; the lower figures indicate the (weighted) patronage for the section during the corresponding periods. 


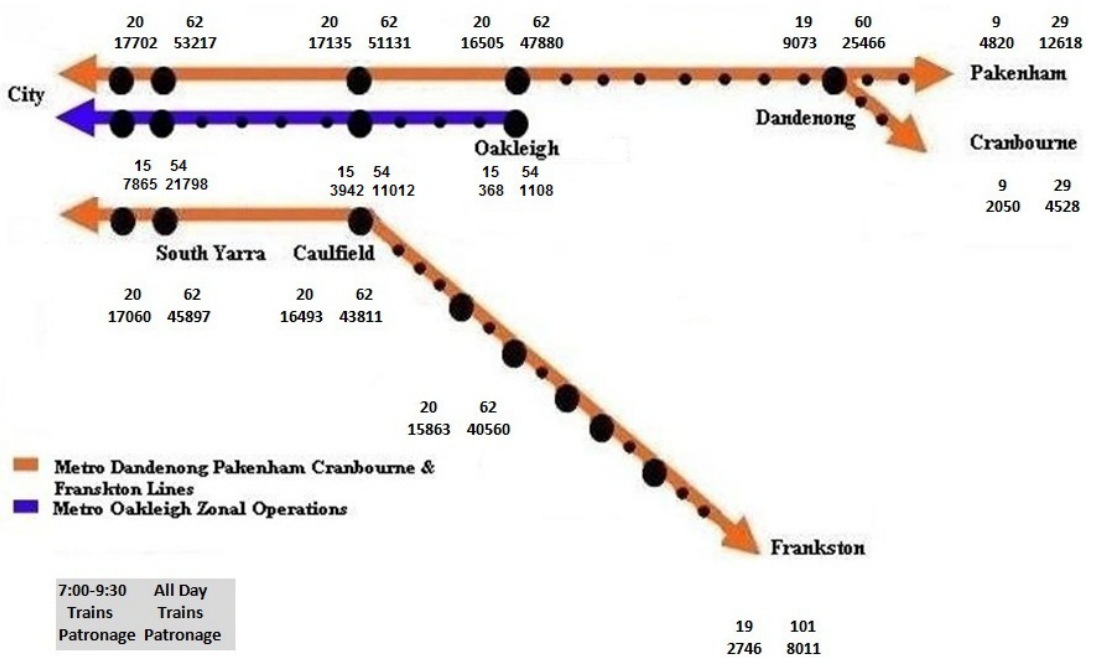

Figure 4: Proposed ZO operations - Oakleigh, Dandenong and Frankston lines.

\section{Discussion}

The implementation of $\mathrm{ZO}$ on the Caulfield Group lines will reduce train traffic along the corridor, improve efficiency of services and reduce overcrowding for train commuters and, in the short-term, accommodate expected increases in patronage, allowing for growth. ZO will permit best practices to be implemented into the network operations; introducing $\mathrm{ZO}$ will also result in a reduction of train traffic entering the City Loop.

Overall, the implementation of ZO reduces Metro's combined level of services from the lines at a common point at Caulfield, from the current 434 scheduled services per day, plus the 27 unscheduled out of service movements every day, to 390 services per day. The reduced train traffic will also have a positive impact at all RLXs along these corridors, mitigating road traffic congestion at all these corridors RLXs.

The contribution of this research and the impact of $\mathrm{ZO}$ can be summarised in the following potential benefits or revelations:

- Would resolve capacity and overcrowding problems on the Dandenong and Frankston lines. It would remove the costly practice of running empty trains from the city to Dandenong and vice versa.

- Dandenong lines service traffic to the City Loop would reduce, freeing the City Loop to all Frankston line services.

- All Oakleigh services will be directed to Flinders St; this means additional Flinders St. traffic and fewer to the City Loop traffic.

- Pakenham and Dandenong lines services would be faster and with fewer stops. Services would run at consistent regular intervals of 7/20/30 service cycles and run express from Oakleigh Station to the City. 
- Frankston line lines services would be faster and with fewer stops. Services would run at consistent and regular intervals of 7/20/30 service cycles and run express from Caulfield Station to the City.

- Oakleigh-City-Oakleigh services would be standard stopping at all stations services. All services would run at consistent and regular intervals with of 10/20/30 service cycles.

- $\quad$ Road commuters would also benefit from $\mathrm{ZO}$; rail traffic reduction would reduce boom gate activity at RLXs, resulting in mitigation of road traffic congestion at all these corridors RLXs.

The implementation of $\mathrm{ZO}$ does have disadvantages, but the resulting benefits surpass the disadvantages of such implementation.

\section{Conclusion}

The implementation of zonal operations on the Caulfield Group of lines would alleviate the current capacity and overcrowding problems facing the corridors, allow for expected increases on train patronage, and help towards resolving capacity problems with the City Loop, as well as mitigating road traffic congestion along the corridors RLXs.

This paper contributes to theory by revealing the use of $\mathrm{ZO}$ to help in resolving capacity and overcrowding problems currently facing the corridors. It also addresses boom gate downtime at RLXs and road traffic congestion issues. In the process, a better understanding is gained on how $\mathrm{ZO}$ and best practices, techniques not in use in the Melbourne rail network, could be used to mitigate road traffic congestion.

\section{References}

[1] KM, Maunsell, and Evans-\&-Peck, "East West Link Needs Assessment (EWLNA) - Transport Supply and Demand". Department of Transport, Victoria, 187, 2008.

[2] M. Webb and S. Gaymer, "Changes in Travel Demand in Melbourne - is it time for a new paradigm?", Australian Transport Research Forum, 16, 2009.

[3] PTV, "Metropolitan Public Transport Demand Forecast Report", Public Transport Victoria 46, 2013.

[4] V. R. Vuchic, Urban Transit: Operations, Planning and Economics, John Wiley \& Sons, 2005.

[5] P. Mees, "How to Double the Capacity of the Dandenong Line without new Infrastructure". Urban Planning Program, University of Melbourne, 2007.

[6] Mees, "Infrastructure constraints or poor service planning? Increasing service to Melbourne's City Loop and Dandenong rail corridor", 30th Australasian Transport Research Forum, 15, 2007.

[7] P. Mees, P. Moriarty, J. Stone, and M. Buxton, "Putting the Public Interest Back into Public Transport”. 2006. 
[8] N. limited Low, "The Debate on Public Transport We Need". Centre for Governance and Management of Urban Transport, 2007.

[9] D. O. Eisele, "Application of Zone Theory to a Suburban Rail Transit Network", Traffic Quarterly, vol. 22, 18, 1968.

[10] D. O. Eisele, "Zone Theory of Suburban Rail Transit Operations: Revisited", Traffic Quarterly, vol. 32, 17, 1978.

[11] P. Mees, "Does Melbourne need another central city rail tunnel?" Environment \& Planning Program, School of Global Studies, Social Science \& Planning, RMIT University, 2008.

[12] PTV. (2013, 31 December). Railway Level Crossings in Victoria 2010.

[13] PTV, "Metropolitan Patronage Demand Forecast". Public Transport Victoria 46, 2013.

[14] DoT/DoI, "Meeting Our Transport Challenges - Connecting Victorian Communities". Department of Infrastructure/Department of Transport, 80, 2006.

[15] J. Stanley and S. Barrett, "Moving People - Solutions for a growing Australia". Report for Australasian Railway Association, Bus Industry Confederation and UITP, 81, 2010.

[16] C. Lucas, "Melbourne's big squeeze", 3, 2009.

[17] Metro, "A time and place for every Metro customer - Pakenham Cranbourne Timetables". Metro Trains \& MetLink, 67, 2011.

[18] G. McNamara and J. J. Cox, "Melbourne - The City of Level Crossings", 30th Annual General Meeting, 34, 1979.

[19] W. Guzman, "Trains come at a price - Boom gates to create road chaos: A Reply”, vol. 2011, 1, 2011.

[20] VicGov, "Plan Melbourne, Metropolitan Planning Strategy", 2013.

[21] VicGov, "Victoria's Submission to Infrastructure Australia", 2012.

[22] Metro, "A time and place for every Metro customer - Pakenham Cranbourne Timetables". Metro Trains \& MetLink, 67, 2013.

[23] Metro, "A time and place for every Metro customer - Frankston Timetables". Metro Trains \& MetLink, 67, 2013.

[24] VLine, "VLine Traralgon Melbourne Traralgon Timetables". VLine, 2, 2013.

[25] PTV, "Estimated Station Entries at Metropolitan Stations - 2008/09 to 2011/12". 2013.

[26] BITRE, "Understanding Australia's urban railways". Department of Infrastructure and Transport, Research Report 131, 134, 2012.

[27] P. Mees, "Melbourne's Future Transport Options - A report to the Melbourne City Council". Faculty of Architecture, Building \& Planning, Melbourne University, 40, 2005.

[28] J. Symons, "Paper 7: Operational and Transport Issues in Rail Passenger Transport". CRC for Rail Innovation, 29, 2009. 